$\mathcal{B} \mathcal{T} \mathcal{P} \mathcal{S}$

Brazilian Transportation Planning Society
Journal of Transport Literature

Vol. 7, n. 1, pp. 182-193, Jan 2013

Reviews \& Essays
JTL | RELIT

www.transport-literature.org ISSN 2238-1031

\title{
Atendimento à população: ônibus urbano no município de São Paulo
}

[Care to the population: urban bus in the city of São Paulo]

\author{
Carlos Paiva* \\ Companhia de Engenharia de Tráfego (CET-SP), Brazil
}

Submitted 21 Jun 2011; received in revised form 11 Jan 2012; accepted 26 Jan 2012

\begin{abstract}
Resumo
Este artigo analisa o modo ônibus no município de São Paulo com base nos dados da Pesquisa Origem e Destino 2007 (OD 2007) de onde obtivemos as seguintes informações: 1) entre 3 e 9\% do total de viagens realizadas em ônibus urbanos no município de São Paulo têm origem ou destino fora da cidade, o que é de se estranhar, já que estes ônibus não deveriam servir estes locais; 2) a região sul e a região noroeste se destacam como geradoras de viagens de ônibus e também por um aumento significativo no número de viagens de autos com destino ao centro expandido, indicando uma possível debilidade do sistema de transporte coletivo. 0 cruzamento dos dados da OD 2007 com os dados das linhas de ônibus (frota, frequência, etc.) gerenciadas pela São Paulo Transportes - SPTrans nos permitiu também construir índices de atendimento à população e identificar vetores de viagens (pares origem/destino) com possíveis problemas de atendimento.
\end{abstract}

Palavras-Chave: transporte urbano; ônibus; São Paulo; atendimento; pesquisa origem-destino.

\begin{abstract}
This paper analyzes the bus transportation mode in the city of São Paulo based on data from the 2007 Origin and Destination Research(OD 2007), which allowed us to obtain the following information: 1) between 3 and $9 \%$ of the total trips in urban bus in the city of São Paulo have origin or destination outside the city, what is very surprising, since these buses should not serve these sites; 2) South and northwest regions stood out as generators of bus rides and also had a significant increase in the number of auto trips to the expanded downtown area, possibly indicating some weakness in the public transportation system. The comparison of data from the 2007 OD with data bus lines (fleet, frequency, etc.) managed by São Paulo Transportes - SPTrans also allowed us to construct indexes of service to the population and identify trip vectors (origin/destination pairs) with likely problems of care.
\end{abstract}

Key words: urban transport; buses; São Paulo; care; origin-destination survey.

*Email: paivacardoso@yahoo.com.br.

\section{Recommended Citation}

Paiva, C. (2013) Atendimento à população: ônibus urbano no município de São Paulo. Journal of Transport Literature, vol. 7, n. 1, pp. 182-193.

- JTL/RELIT is a fully electronic, peer-reviewed, open access, international journal focused on emerging transport markets and published by BPTS - Brazilian Transport Planning Society. Website www.transport-literature.org. ISSN 2238-1031.

This paper is downloadable at www.transport-literature.org/open-access. 


\section{Introdução}

Este artigo analisa o modo ônibus no município de São Paulo com base nos dados da Pesquisa Origem e Destino Domiciliar 2007 (OD 2007) ${ }^{1}$ e, nas frequiências e frotas das linhas de ônibus gerenciadas pela São Paulo Transportes - SPTrans ${ }^{2}$. Diferentemente das Pesquisas Origem e Destino anteriores (1897 e 1997), nesta pesquisa, os modos ônibus e microônibus foram subdivididos em: ônibus e microônibus do município de São Paulo; ônibus e microônibus de outros municípios da Região Metropolitana de São Paulo, excluindo-se os da cidade de São Paulo e ônibus e microônibus metropolitanos (aqueles que realizam viagens intermunicipais).

As pesquisas origem/destino da Região Metropolitana de São Paulo identificam para uma mesma viagem até quatro possíveis modos de transporte, ou seja, o individuo para chegar ao seu destino pode utilizar os modos trem, ônibus, metrô e ônibus ou, unicamente, o modo ônibus, por exemplo. Definiu-se, para facilitar a tabulação dos dados, uma variável denominada modo principal, que estabelece, entre os modos utilizados, uma hierarquia ${ }^{3}$ que é utilizada pelo Metrô - SP. Esta variável considera a viagem como pertencente unicamente ao modo de maior hierarquia.

\section{Análise da Origem e Destino das Viagens}

Para a tabulação (agregação dos dados disponíveis por viagem) do modo ônibus no município de São Paulo utilizamos dois métodos: 1) Modo Principal: só se considera a viagem de ônibus no município de São Paulo quando, entre os modos utilizados na viagem, este é o de hierarquia mais alta. É importante ressaltar que isto só não ocorre quando um dos modos da viagem é trem ou metrô; 2) Todos os Modos: neste caso, considera-se a viagem como

1 Vide descrição detalhada no Anexo a este trabalho.

2 SPtrans - Empresa que gerencia todas as 1300 linhas de ônibus da cidade de São Paulo. O sistema é administrado por 16 consórcios, formados por empresas privadas e cooperativas, responsáveis pela operação de 15 mil veículos.

3 Hierarquia dos Modos (definida pelo Metrô - SP através da variável denominada modo principal), em ordem "decrescente" é a seguinte: metrô, trem, transporte fretado, transporte escolar, ônibus, lotação, táxi, dirigindo automóvel, passageiro de automóvel, moto, bicicleta, outros e a pé. 
pertencente a este modo quando ela ocorre em pelo menos um dos possíveis quatro modos da viagem.

Além dos dois métodos comentados optou-se também por realizar a tabulação do modo ônibus no município de São Paulo para duas amplitudes geográficas: 1)Todas as Zonas: toda a Região Metropolitana de São Paulo (RMSP); 2) Só para São Paulo: zonas OD pertencentes ao município de São Paulo.

A segunda opção de tabulação tornou-se necessária à medida que se verificou a existência de trechos de viagens que utilizavam o modo ônibus no município de São Paulo com origem e/ou destino fora do município de São Paulo. Este tipo de tabulação só é possível na OD 2007, pois esta pesquisa levantou, além da origem e destino das viagens, os pontos de transferência entre os modos de transporte, que, por sua vez, identificam a origem e o destino do trecho da viagem referente a cada modo.

Na tabela a seguir temos os dados do modo ônibus no município de São Paulo, Pesquisa OD 2007, tabulados segundo os métodos (todos os modos e modo principal) e as amplitudes geográficas (Todas Zonas - RMSP e Só São Paulo - unicamente o município de São Paulo) descritos nos dois parágrafos anteriores.

Tabela 01 - modo ônibus no município de São Paulo, Pesquisa OD 2007

\begin{tabular}{|c|c|c|c|c|}
\cline { 2 - 5 } \multicolumn{1}{c|}{} & \multicolumn{4}{c|}{ Amplitude Geográfica } \\
\hline Método de Tabulação & Todas Zonas & Só São Paulo & $\begin{array}{l}\text { Diferença } \\
\text { Absoluta }\end{array}$ & Diferença \% \\
\hline Todos Modos & $5,411,312$ & $5,220,448$ & $\mathbf{1 9 0 , 8 6 4}$ & $\mathbf{3 . 5 \%}$ \\
\hline Modo principal & $5,058,854$ & $4,625,783$ & $\mathbf{4 3 3 , 0 7 1}$ & $\mathbf{8 . 6 \%}$ \\
\hline Diferença Absoluta & $\mathbf{3 5 2 , 4 5 8}$ & $\mathbf{5 9 4 , 6 6 5}$ & \multicolumn{1}{c}{} \\
\hline Diferença \% & $\mathbf{6 . 5 \%}$ & $\mathbf{1 1 . 4 \%}$ \\
\cline { 1 - 4 }
\end{tabular}


Da tabela 01 é possível inferir que:

1. A diferença absoluta do método de tabulação nos mostra que, nas duas amplitudes geográficas, entre 350 mil (todas as zonas - RMSP) e 600 mil viagens ao dia (só São Paulo), de 6 a 12\% do total de viagens do modo ônibus no município de São Paulo, utilizam o modo coletivo urbano sobre pneus integrados com os modos metrô e/ou trem ${ }^{4}$;

2. A diferença absoluta do método da amplitude geográfica nos mostra que, para os diferentes métodos de tabulação, existem de 190 mil (todos os modos) a 430 mil viagens (modo principal) com origem ou destino fora do município de São Paulo (entre 3 a 9\% do total) que podem ser explicadas por uma ou pelo conjunto das seguintes alternativas: a) possíveis erros nas respostas dos entrevistados, que não conseguiram distinguir entre ônibus urbanos do município de São Paulo e outros municípios e/ou interurbanos; b) os entrevistados moram nas imediações do limite do município de São Paulo e caminham até um ponto de ônibus dentro do município, com possível erro na localização da origem e/ou destino da viagem; c) as empresas gerenciadas pela SPTrans atravessam o limite do município para obter um maior número de passageiros.

Para melhor compreensão deste conjunto de viagens do modo ônibus no município de São Paulo com origem e/ou destino fora da cidade, a seguir (figura 01) temos a distribuição espacial destas viagens, gerenciados pela SPTrans (cerca de 200 mil viagens ao dia).

4 O campo diferença absoluta da tabela 01permite identificar quantas são as viagens de ônibus integradas aos modos trem e/ou metrô porque quando a tabulamos do modo ônibus pelo modo principal, o modo ônibus só é contado quando entre os quatro possíveis modos utilizados em uma viagem não existem os modos metrô e/ou trem, já que na hierarquia dos modos estes têm prioridade sobre o modo ônibus; por exemplo, uma viagem realizada de trem e ônibus é contada como trem. 
Figura 01 - Origem das Viagens

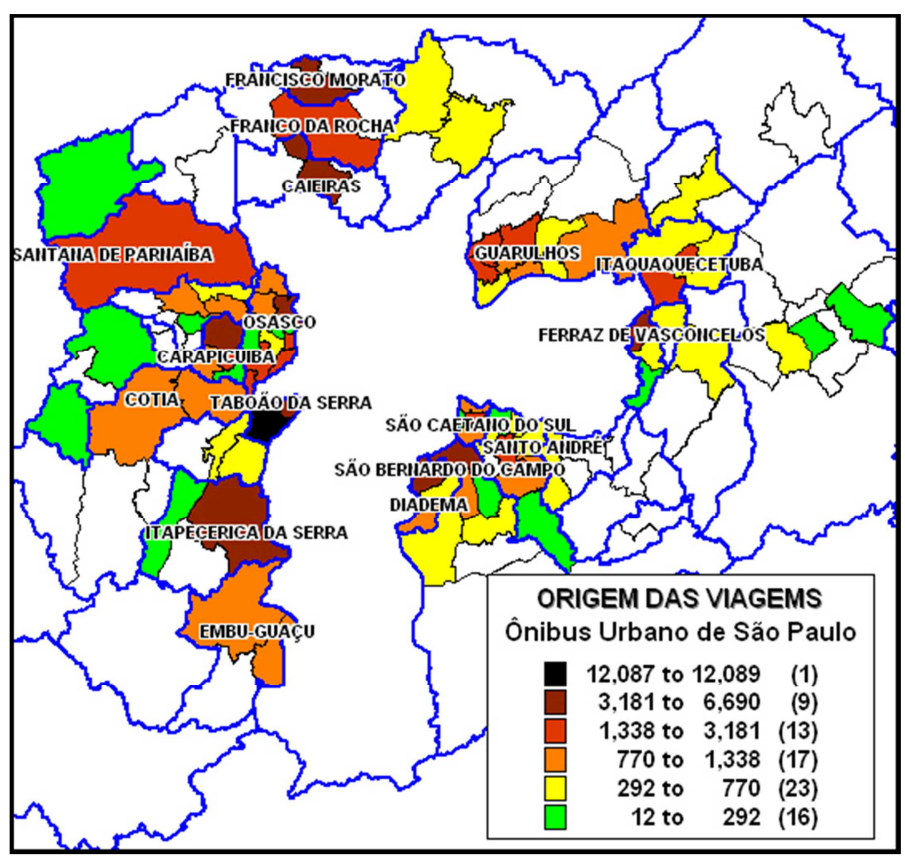

Observa-se que o número de viagens com origem na Região Metropolitana (fora de São Paulo) em algumas regiões é bastante expressivo. Destacam-se os municípios de Taboão da Serra, com mais de 12 mil viagens; Francisco Morato, com quase 7 mil viagens (não tem fronteira com São Paulo); São Bernardo do Campo e Caieiras, com aproximadamente 5 mil viagens ao dia.

A figura 02 mostra a distribuição da origem das mais de 5 milhões e 200 mil viagens/dia do modo ônibus urbano na cidade de São Paulo: 
Figura 02 - Origem das viagens de ônibus internas à cidade São Paulo

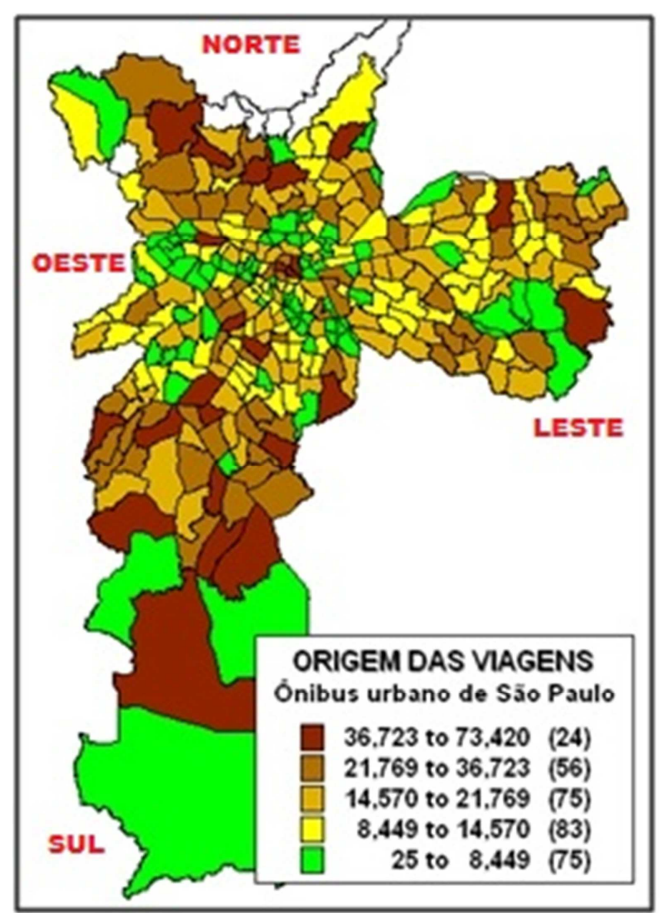

Algumas regiões se destacam como geradoras de viagens (tons de marrom), como a região sul e a região noroeste. Análise da pesquisa OD 2007 nos permite afirmar que estas regiões tiveram, entre 1997 e 2007, um aumento significativo no número de viagens de auto com destino ao centro expandido ${ }^{5}$ ( 20 mil no sul e 30 mil no noroeste). Este contraponto, ônibus versus auto, pode significar debilidades no sistema de transporte coletivo que precisam ser estudadas e corrigidas.

5 A região do centro expandido da cidade de São Paulo, limitada pelo minianel viário (formado pelas marginais Tietê e Pinheiros, Avenida dos Bandeirantes, Avenida Afonso D'Escragnole Taunay, Complexo Viário Maria Maluf, Avenida Tancredo Neves, Avenida das Juntas Provisórias, Viaduto Grande São Paulo, Avenida Professor Luís Inácio de Anhaia Mello e Avenida Salim Farah Maluf), é considerada uma das áreas mais problemáticas da Região Metropolitana de São Paulo (RMSP), no que se refere ao trânsito. 


\section{Análise do Atendimento dos Principais Vetores de Viagens}

Com base no zoneamento da Pesquisa OD 2007 analisamos a seguir os principais vetores de viagens de ônibus urbano na cidade de São Paulo - pares origem/destino (pares OD).

Figura 03 - Principais pares OD de viagens de ônibus urbano na cidade de São Paulo

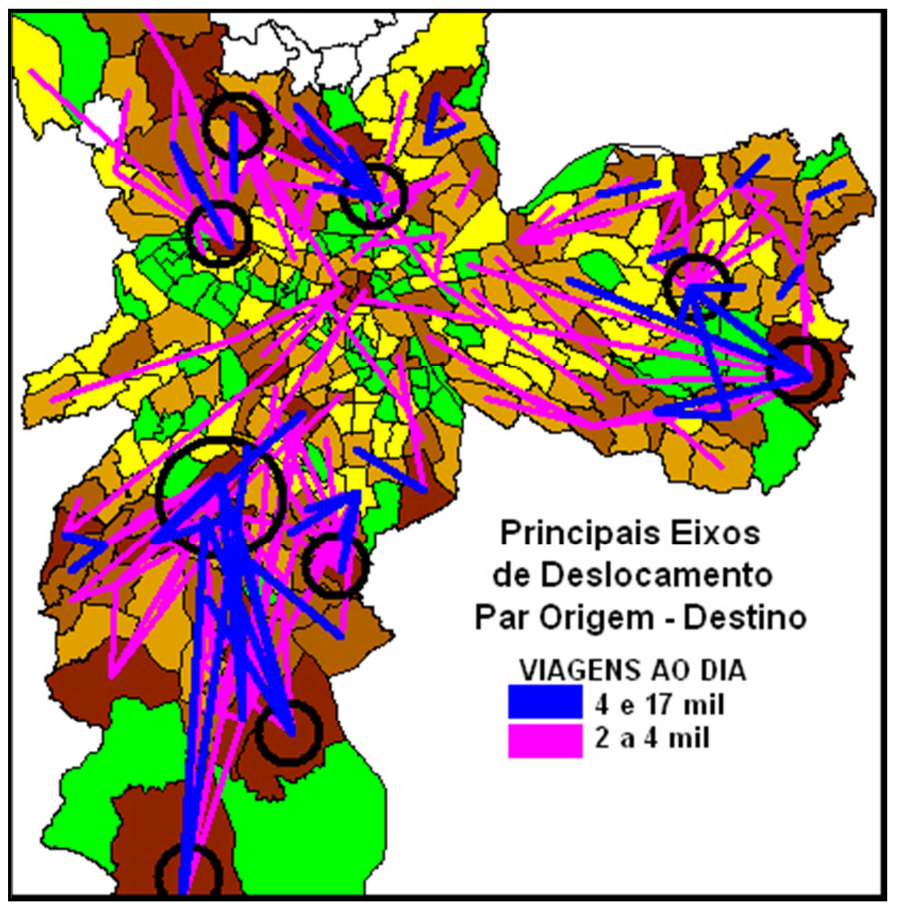

É possível observar que algumas regiões (círculos pretos) se destacam como origem de eixos de viagem (par OD) com alto volume, coincidentes, em muitos casos, com zonas de alta geração de viagens de ônibus urbano.

Com o objetivo de avaliar o atendimento destas viagens (pares origem/destino com um volume expressivo) vamos comparar estes volumes com os dados de freqüência e frota das linhas dos ônibus urbanos que servem estas zonas.

Para esta análise foram identificadas, para cada par OD, todas as linhas que permitem este deslocamento (não foi avaliada a possibilidade de transbordo) e, somou-se a frequiência e a frota de ônibus disponíveis nestas linhas. Os volumes de viagens destes eixos de deslocamento (par OD) foram divididos pela freqüência total e frota total que servem cada eixo de viagem, obtendo-se assim dois índices de atendimento - Índice 01 = Número de Viagens/Frequência Total e Índice 02 = Número de Viagens/Frota Total. 
As linhas que servem cada par OD não permitem apenas este deslocamento. Todas as linhas de ônibus urbanos do município de São Paulo permitem o deslocamento entre diversos pares OD, o que torna a ocupação dos ônibus dependente da contribuição de todos os pares OD servidos pelas rotas das linhas e, não só do par OD analisado. Mesmo com limitações quanto aos índices obtidos, podemos afirmar que quanto maior o valor para os índices de atendimento, maior será a possibilidade de uma ocupação acima do aceitável neste trecho das linhas.

A seguir, na figura 04 e tabela 02 , mostramos os pares OD onde o índice de atendimento número 1 (Número de Viagens/Frequência Total) proposto indicou possíveis problemas:

Figura 04 - Índice de Atendimento 01

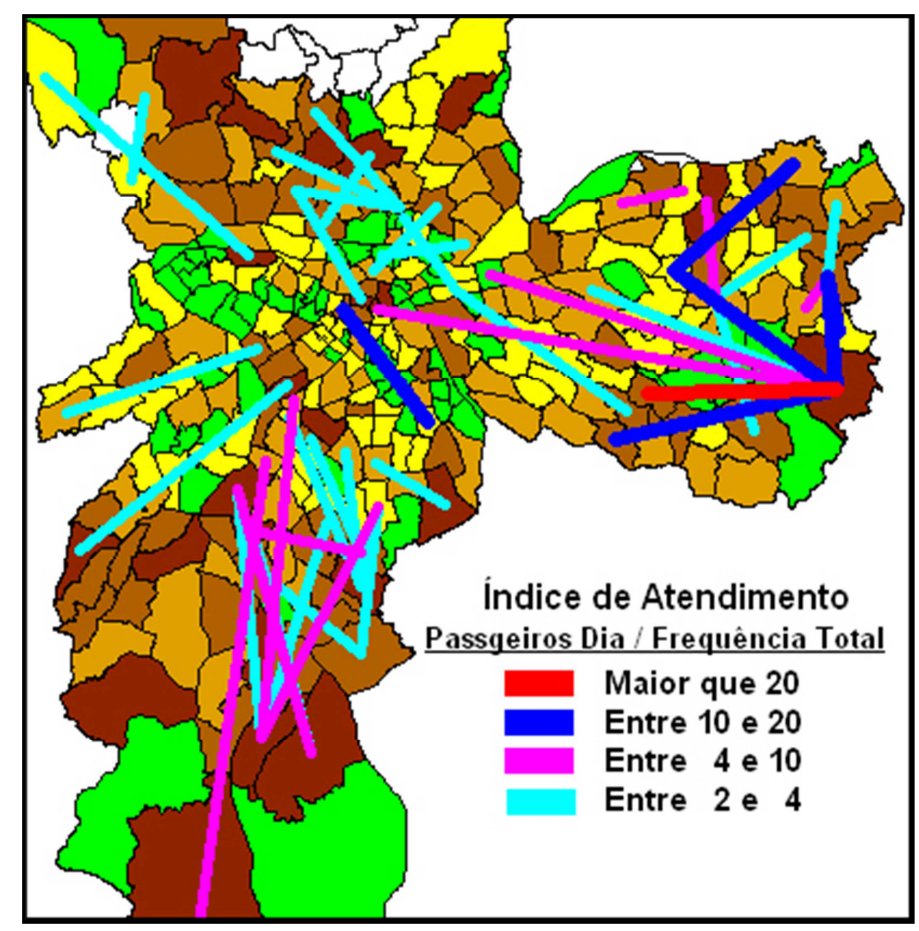


Tabela 02 - Índice de Atendimento 01 e $^{02^{6}}$

\begin{tabular}{|c|c|c|c|c|c|c|}
\hline Zona Origem & Zona Destino & Viagens Dia & Frequência Total & Frota Total & Índice 1 * & Índice 2 ** \\
\hline 217 & 248 & 3796 & 166 & 32 & 22.9 & 118.6 \\
\hline 31 & 224 & 2466 & 144 & 22 & 17.1 & 112.1 \\
\hline 243 & 217 & 2916 & 194 & 60 & 15.0 & 48.6 \\
\hline 217 & 243 & 2503 & 194 & 60 & 12.9 & 41.7 \\
\hline 188 & 205 & 3562 & 278 & 47 & 12.8 & 75.8 \\
\hline 217 & 193 & 2433 & 215 & 28 & 11.3 & 86.9 \\
\hline 216 & 193 & 2333 & 215 & 28 & 10.9 & 83.3 \\
\hline 205 & 217 & 2448 & 238 & 34 & 10.3 & 72.0 \\
\hline 217 & 205 & 2448 & 274 & 34 & 8.9 & 72.0 \\
\hline 217 & 1 & 2269 & 274 & 112 & 8.3 & 20.3 \\
\hline 217 & 165 & 2007 & 294 & 98 & 6.8 & 20.5 \\
\hline 71 & 279 & 4288 & 737 & 152 & 5.8 & 28.2 \\
\hline 179 & 182 & 2486 & 450 & 72 & 5.5 & 34.5 \\
\hline 281 & 276 & 4856 & 882 & 216 & 5.5 & 22.5 \\
\hline 193 & 215 & 5792 & 1063 & 138 & 5.4 & 42.0 \\
\hline 275 & 68 & 2244 & 452 & 118 & 5.0 & 19.0 \\
\hline 170 & 176 & 5133 & 1074 & 216 & 4.8 & 23.8 \\
\hline 275 & 258 & 3654 & 845 & 168 & 4.3 & 21.8 \\
\hline 215 & 193 & 4298 & 1063 & 138 & 4.0 & 31.1 \\
\hline 259 & 283 & 2786 & 696 & 112 & 4.0 & 24.9 \\
\hline
\end{tabular}

Índice 01 - Número de Viagens / Frequência Total Índice 02 - Número de Viagens / Frota Total

Nesta tabela, a ordem das cores - vermelho (pior caso), azul e lilás (menos problemático) identifica, entre os quase 500 pares OD analisados (com mais de 2 mil viagens ao dia), aqueles com uma pior taxa de ocupação do trecho. O par OD de cor vermelha (da zona 217 Cidade Tiradentes para a zona 248 - Cidade IV Centenário e vice-versa), por exemplo, mostrou um alto índice de ocupação (índice $01=23$ ) somente devido às viagens entre estas zonas.

6 Nomes das Zonas:

\begin{tabular}{|c|c|c|c||}
\hline Zona & Nome & Zona & Nome \\
\hline $\mathbf{1}$ & Sé & $\mathbf{2 1 6}$ & Juscelino Kubitschek \\
\hline $\mathbf{3 1}$ & Vila Buarque & $\mathbf{2 1 7}$ & Cidade Tiradentes \\
\hline $\mathbf{6 8}$ & Vila Olimpia & $\mathbf{2 2 4}$ & Alto do Ipiranga \\
\hline $\mathbf{7 1}$ & Vila Cordeiro & $\mathbf{2 4 3}$ & Parque Sta Madalena \\
\hline $\mathbf{1 6 5}$ & Chácara do Piqueri & $\mathbf{2 4 8}$ & Cidade IV Centenário \\
\hline $\mathbf{1 7 0}$ & Rui Barbosa & $\mathbf{2 5 8}$ & Cidade Vargas \\
\hline $\mathbf{1 7 6}$ & Parque Buturussu & $\mathbf{2 5 9}$ & Jardim Bom Clima \\
\hline $\mathbf{1 7 9}$ & Limoeiro & $\mathbf{2 7 5}$ & Grajaú \\
\hline $\mathbf{1 8 2}$ & Itaquera & $\mathbf{2 7 6}$ & Cocaia \\
\hline $\mathbf{1 8 8}$ & Jardim Helena & $\mathbf{2 7 9}$ & Parelheiros \\
\hline $\mathbf{1 9 3}$ & Fabrica Bandeirantes & $\mathbf{2 8 1}$ & Granja Julieta \\
\hline $\mathbf{2 0 5}$ & Cidade A.E.Carvalho & $\mathbf{2 8 3}$ & Santo Amaro \\
\hline $\mathbf{2 1 5}$ & Guaianazes & & \\
\hline
\end{tabular}




\section{Conclusões}

Este artigo analisou o modo ônibus na cidade de São Paulo com base nos dados da pesquisa OD 2007 e encontrou indícios de problemas, como, por exemplo, viagens realizadas em ônibus urbanos pertencentes ao município de São Paulo com origem e/ou destino fora da cidade; regiões geradoras de viagens de ônibus com aumento significativo no número de viagens de auto, dentre outros, que merecem ser analisados pelo poder público.

Através das análises das duas bases de dados (OD 2007 e linhas gerenciadas pela SPTrans) definimos índices de atendimento que permitiram identificar possíveis problemas em vetores de viagens existentes no sistema de transporte coletivo por ônibus no município de São Paulo. Os pares OD identificados devem ser estudados pelo poder público, para que os problemas detectados possam ser minimizados.

\section{Referências}

Paiva, C. (2011) Evolução dos tempos das viagens do modo trem na Região Metropolitana de São Paulo. Journal of Transport Literature, vol. 5, n. 3, pp. 182-191. 


\section{Anexo}

A Pesquisa Origem e Destino, ou simplesmente Pesquisa OD, é realizada desde 1967 na Região Metropolitana de São Paulo - RMSP, com periodicidade de dez anos e, tem por objetivo o levantamento de informações atualizadas sobre as viagens realizadas pela população da metrópole em dia útil típico. Constitui-se no principal instrumento de coleta de informações sobre viagens, servindo de base para os estudos de planejamento de transporte.

A Pesquisa Origem e Destino é o resultado de duas pesquisas distintas e complementares, denominadas Pesquisa Domiciliar e Pesquisa na Linha de Contorno. A primeira levanta os dados sobre as viagens internas à área de pesquisa - RMSP; a segunda levanta os dados das viagens externas, com origem ou destino no interior da área de pesquisa e, ainda, as viagens que simplesmente atravessam a área de pesquisa.

A Pesquisa Origem e Destino 2007 Domiciliar foi realizada no período de agosto a novembro de 2007, com complementação no período de fevereiro a abril de 2008, quando foram visitados 54.500 domicílios, resultando em aproximadamente 30.000 domicílios com entrevistas consideradas válidas.

A Região Metropolitana de São Paulo, constituída por 39 municípios, foi dividida em 460 zonas de pesquisa, sendo o município de São Paulo, composto de 96 distritos, foi dividido em 320 zonas. O esquema de amostragem estratificada adotado permitiu a obtenção de totais de viagens produzidas em cada zona OD, com margens de erro inferiores a $5 \%$ e nível de confiança de $95 \%$. Para algumas poucas zonas, onde não foi possível a utilização do esquema estratificado, adotou-se a amostragem casual simples, cujos erros ficaram em torno de 7,5\%.

Os principais conceitos e informações contidos na Pesquisa Origem Destino Domiciliar são: Viagem: movimento de uma pessoa entre dois pontos (origem e destino), com motivo definido e, utilizando para isso, um ou mais modos de transporte; Modos de Transporte utilizados nas viagens:

1. Modo Coletivo: metrô, trem, ônibus, ônibus fretado, escolar e lotação;

2. Modo Individual: motorista de automóvel, passageiro de automóvel, táxi, caminhão, moto, bicicleta e outros; 
3. Modo a pé: viagem realizada a pé da origem ao destino quando a distância percorrida for superior a 500 metros (5 quadras). Quando o motivo da viagem é trabalho ou escola, a viagem é registrada independentemente da distância percorrida;

4. Modo principal: é o modo de maior hierarquia dentre os utilizados na mesma viagem (veja nota 3 - Hierarquia dos Modos)

5. Modo motorizado: soma das viagens dos modos coletivo e individual;

Dados Socioeconômicos: posse de auto, trabalho, idade, sexo, etc., das famílias e pessoas entrevistadas. 